\title{
Total Synthesis of Pinnamine and Anatoxin-a via a Common Intermediate. A Caveat on the Anatoxin-a Endgame
}

\section{Thonas Hjelmgaar, Inger Sotofte and David Tamer}

\section{Contents}

S1: General Experimental methods

S2: ${ }^{1} \mathrm{H}$ NMR spectrum of $\mathbf{1}$

S3: ${ }^{13} \mathrm{C}$ NMR spectrum of $\mathbf{1}$

S4: COSY spectrum of $\mathbf{1}$

S5: ${ }^{1} \mathrm{H}$ NMR spectrum of $\mathbf{2}$

S6: ${ }^{13} \mathrm{C}$ NMR spectrum of 2

S7: ${ }^{1}$ H NMR spectrum of $\mathbf{1 9}$

S8: COSY spectrum of 19

S9: ${ }^{1}$ H NMR spectrum of $\mathbf{2 1}$

S10: ${ }^{13} \mathrm{C}$ NMR spectrum of $\mathbf{2 1}$

\section{General Experimental Methods}

THF, $\mathrm{Et}_{2} \mathrm{O}$ and toluene were distilled under $\mathrm{N}_{2}$ from Na-benzophenone. $\mathrm{CH}_{2} \mathrm{Cl}_{2}, \mathrm{Et}_{3} \mathrm{~N},{ }^{i} \mathrm{Pr}_{2} \mathrm{NH}$ were dried over $\mathrm{CaH}_{2}$ and distilled under $\mathrm{N}_{2}$. $\mathrm{MeCN}, c$-hexane, $\mathrm{MeOH}, \mathrm{EtOH}, N$-ethylpiperidine and ${ }^{i} \mathrm{Pr}_{2} \mathrm{NEt}$ were dried over $4 \AA$ molecular sieves. All other solvents and chemicals were of reagent grade and were, unless otherwise stated, used without further purification. Melting points are uncorrected. Specific rotations were measured on a polarimeter using a $10 \mathrm{~cm}$ cell.

For IR spectra $v$ are expressed in $\mathrm{cm}^{-1} .{ }^{1} \mathrm{H}$ NMR spectra were recorded on a $300 \mathrm{MHz}$ spectrometer. Chemical shifts are referenced to the residual solvent peak. Where applicable, assignments were based on DEPT and COSY-experiments. TLC was performed on Merck TLC aluminum sheets, silicagel $60, \mathrm{~F}_{254}$.

Progression of reactions where, when applicable, followed by TLC and/or NMR. Visualizing of spots was effected with UV-light and/or ninhydrin in $n$ - $\mathrm{BuOH} / \mathrm{AcOH}$ and/or $1.5 \% \mathrm{NH}_{4} \mathrm{Mo}_{2} \mathrm{O}_{2} / 1 \% \mathrm{Ce}\left(\mathrm{SO}_{4}\right)_{2} / 10 \%$ $\mathrm{H}_{2} \mathrm{SO}_{4}$ in EtOH. Flash chromatography was performed with silica gel 60, 0.035-0.070 mm, Amicon 85040. Unless otherwise stated, flash chromatography was performed in the eluent system, for which the $\mathrm{R}_{f}$-values are given. 

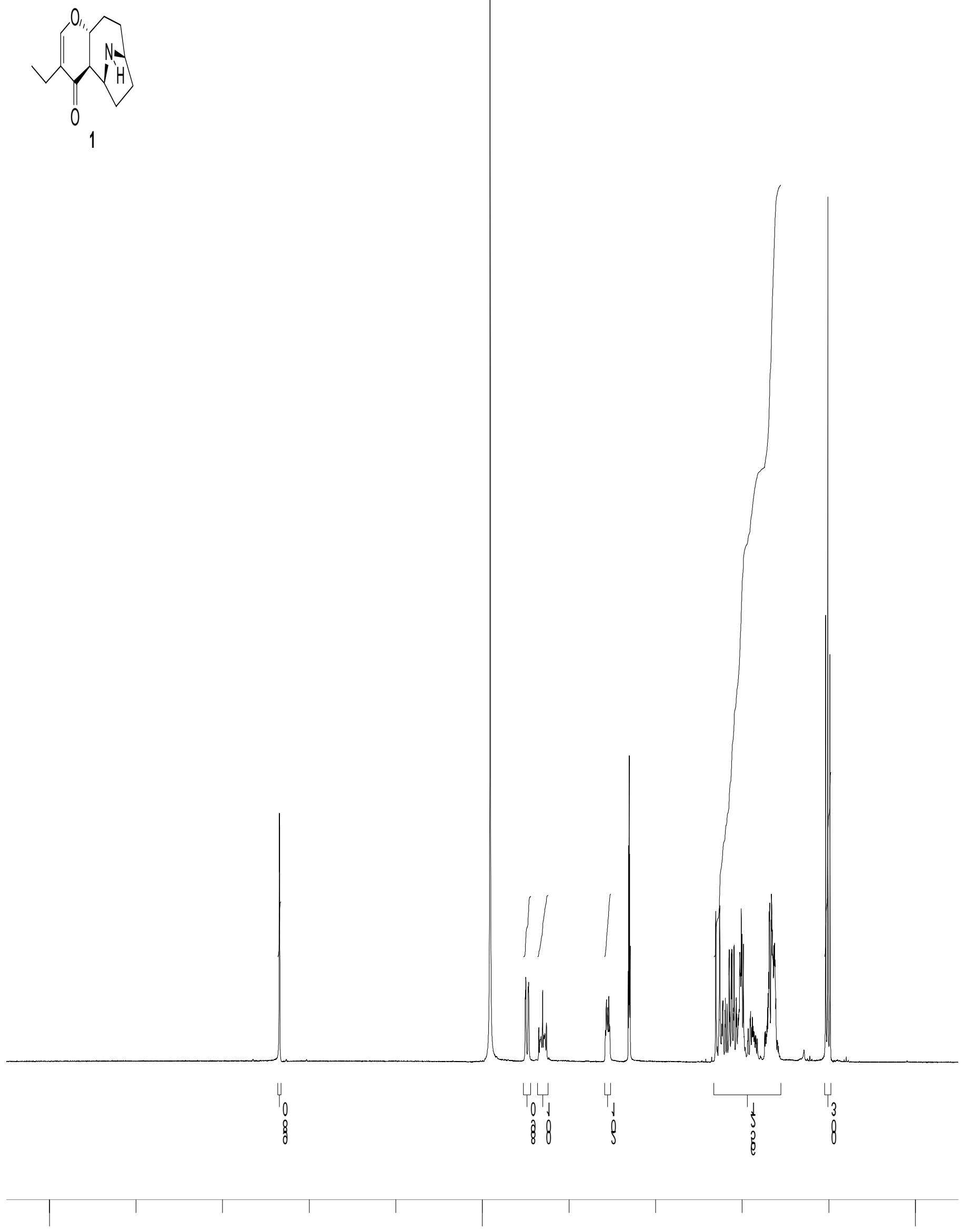

$\begin{array}{ll}q & j \\ 2 & j \\ j & j\end{array}$

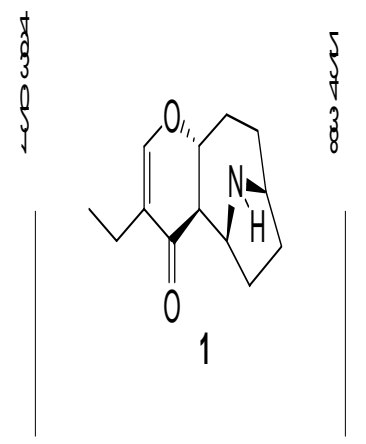

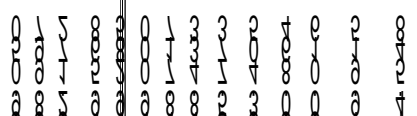

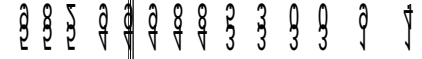
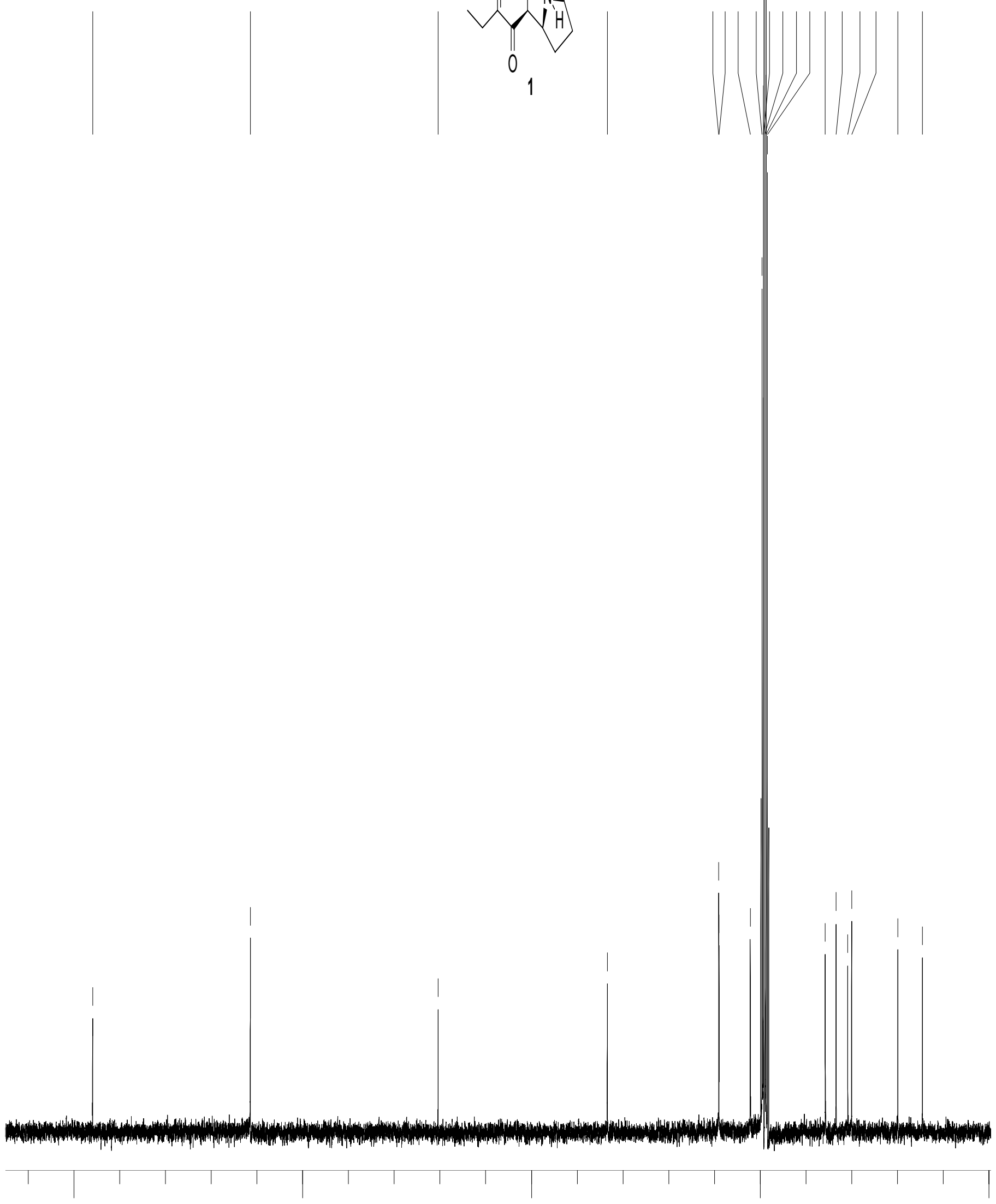



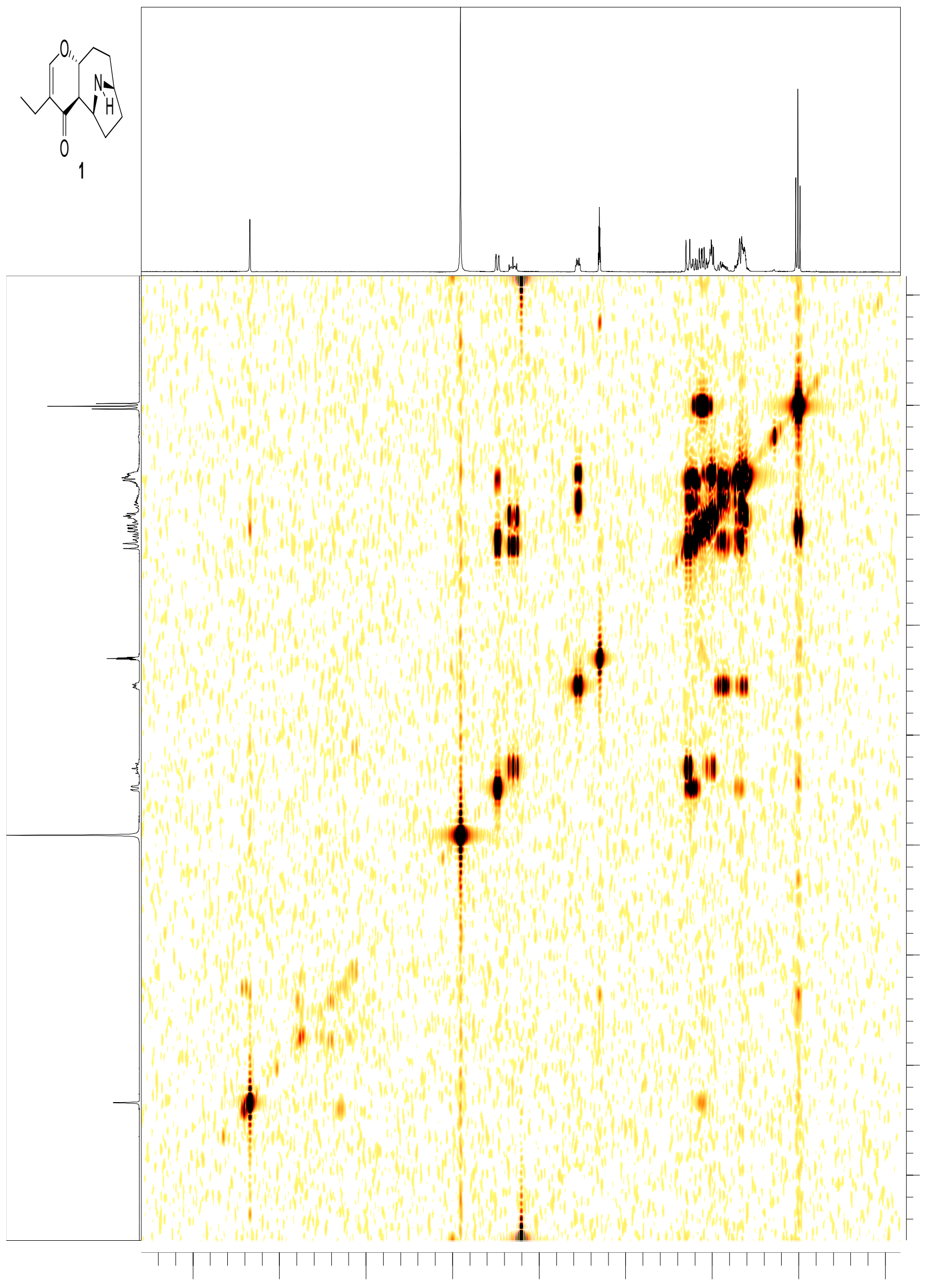



${ }_{2}$
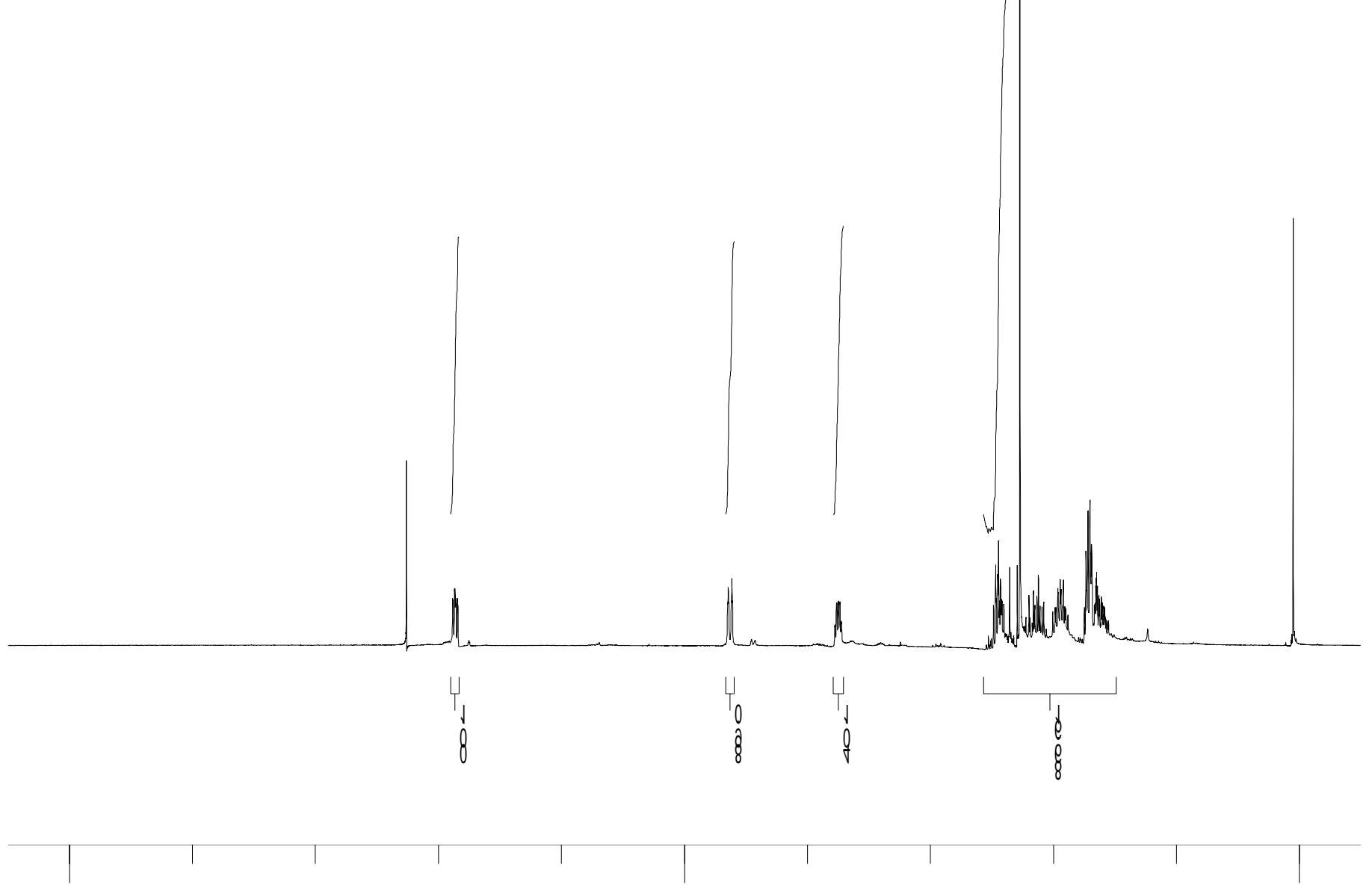



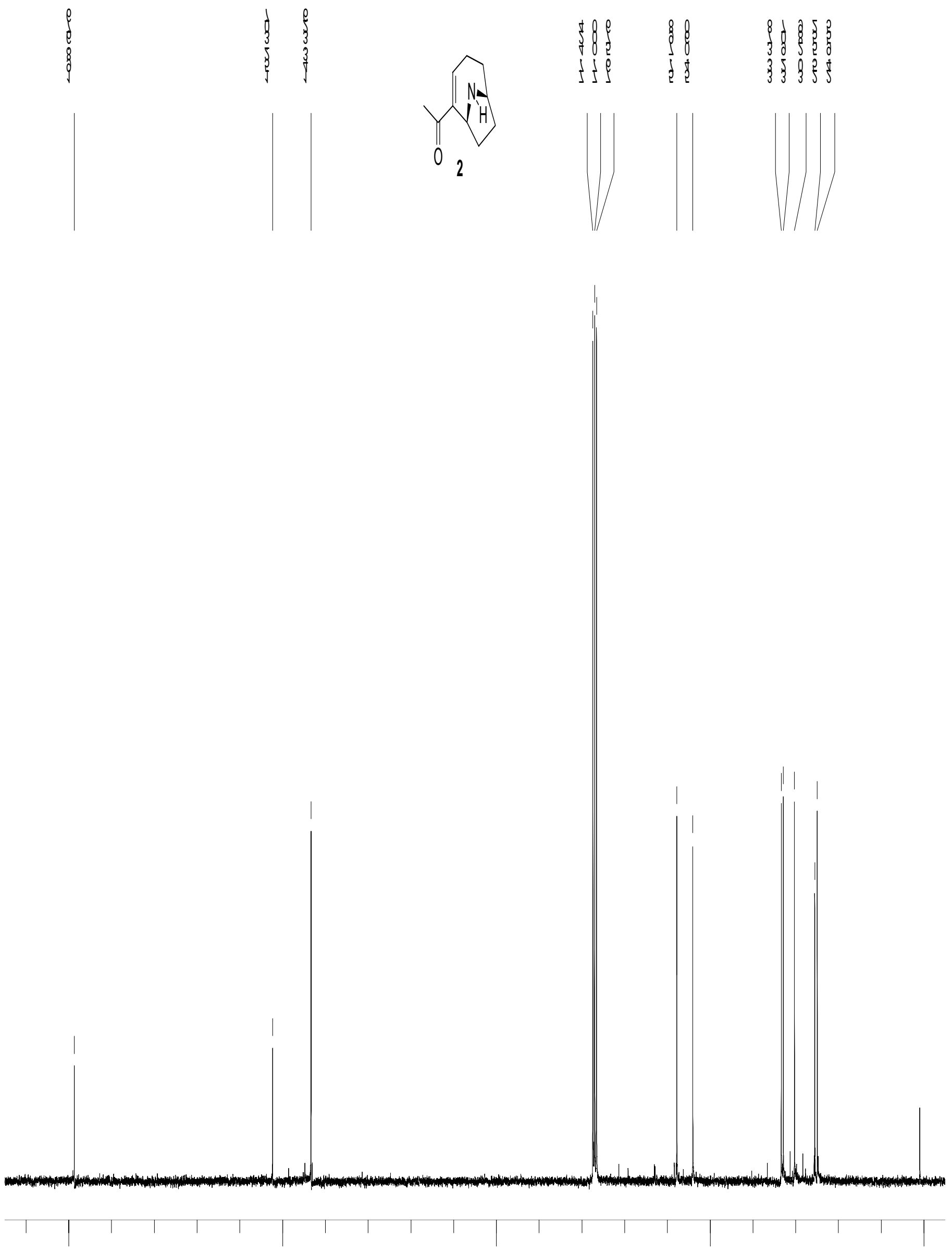





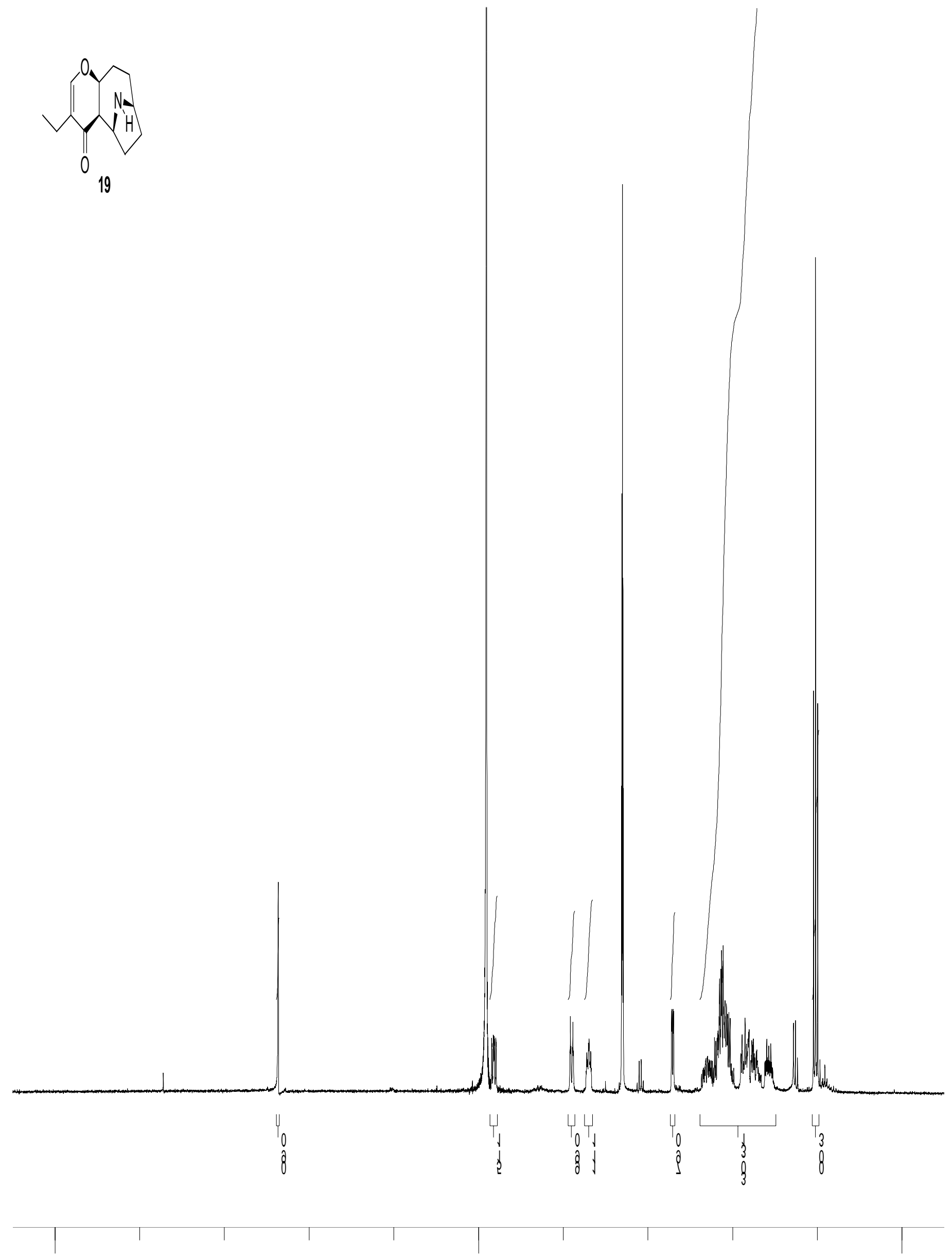

S7 



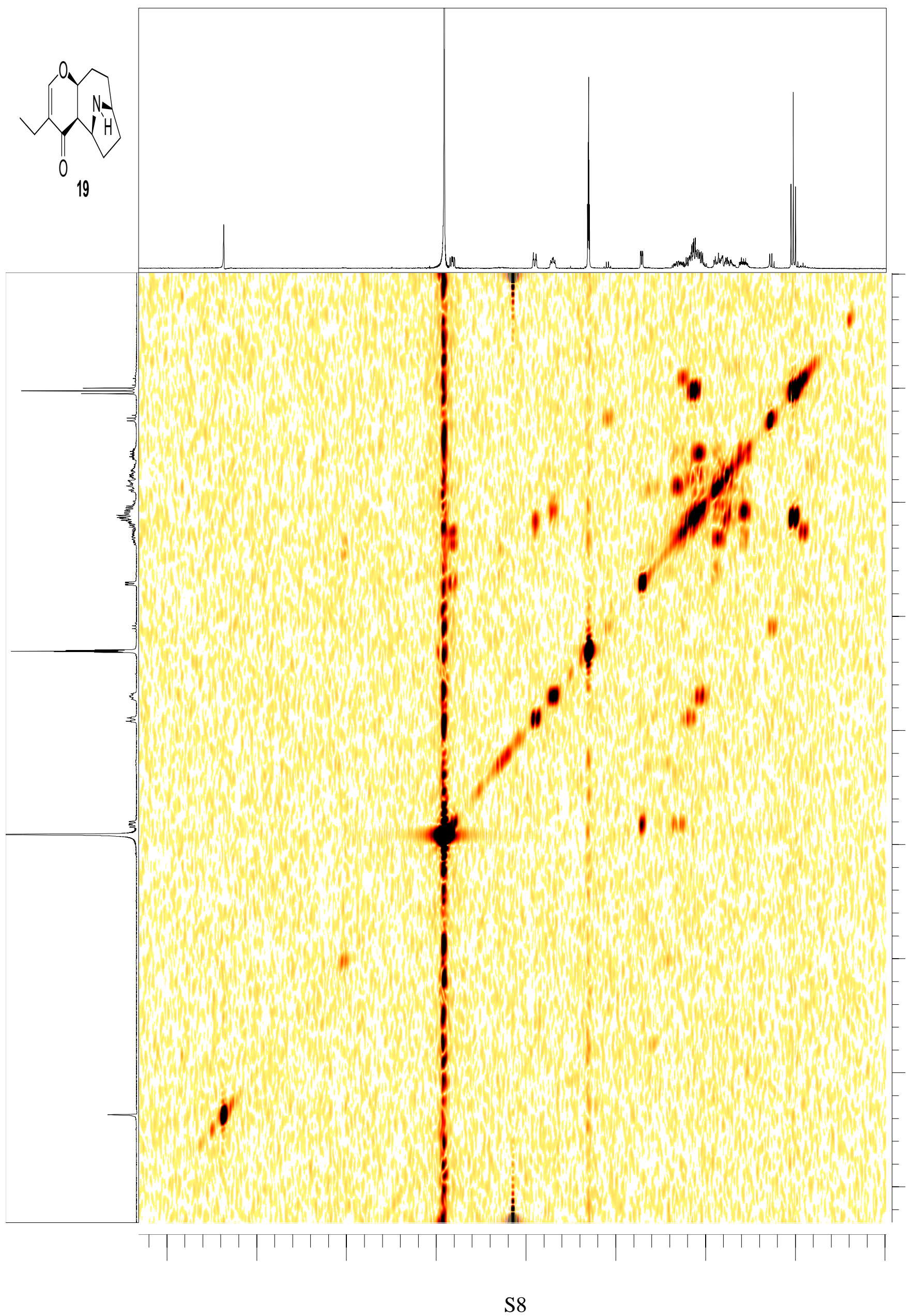




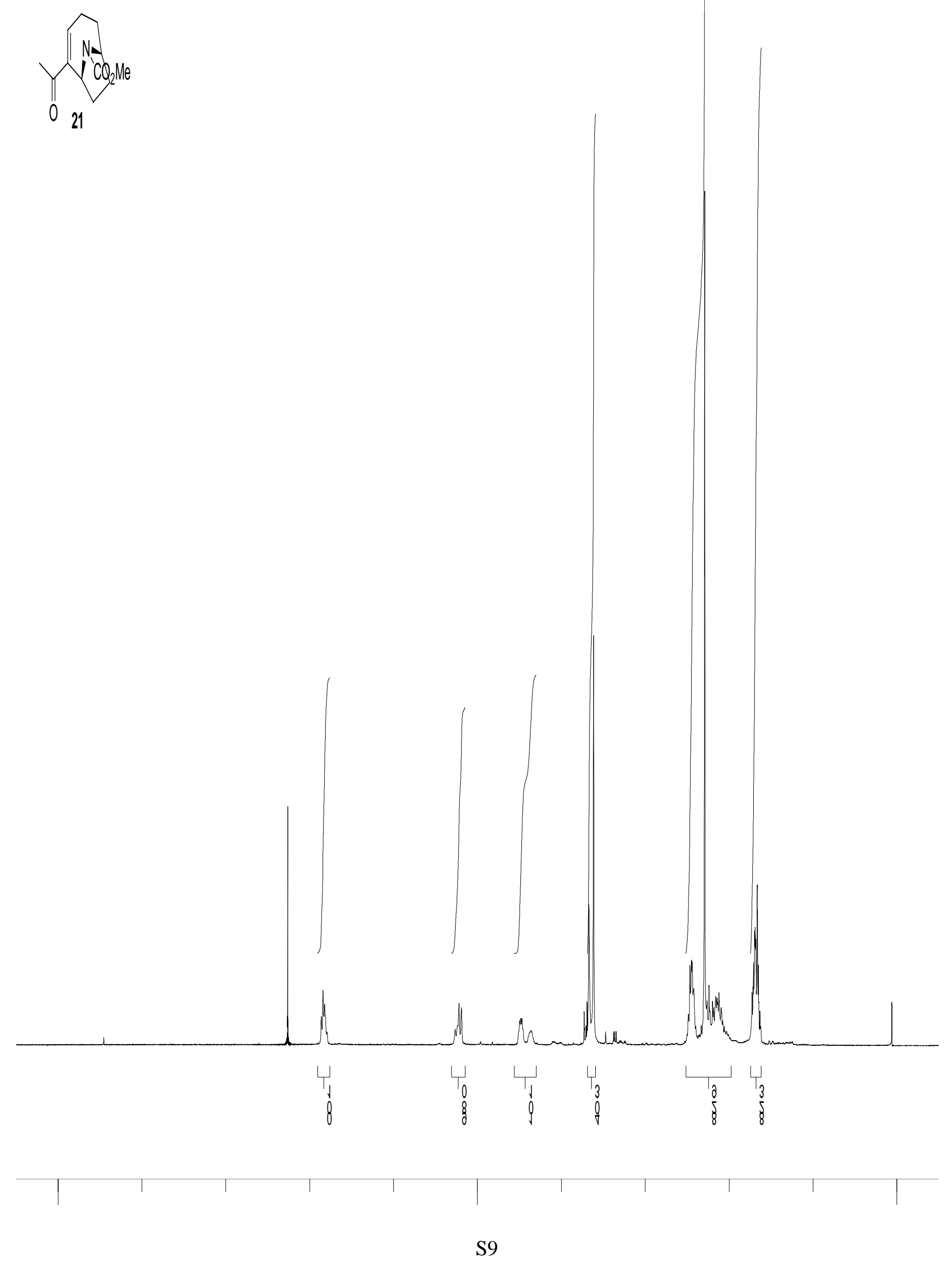



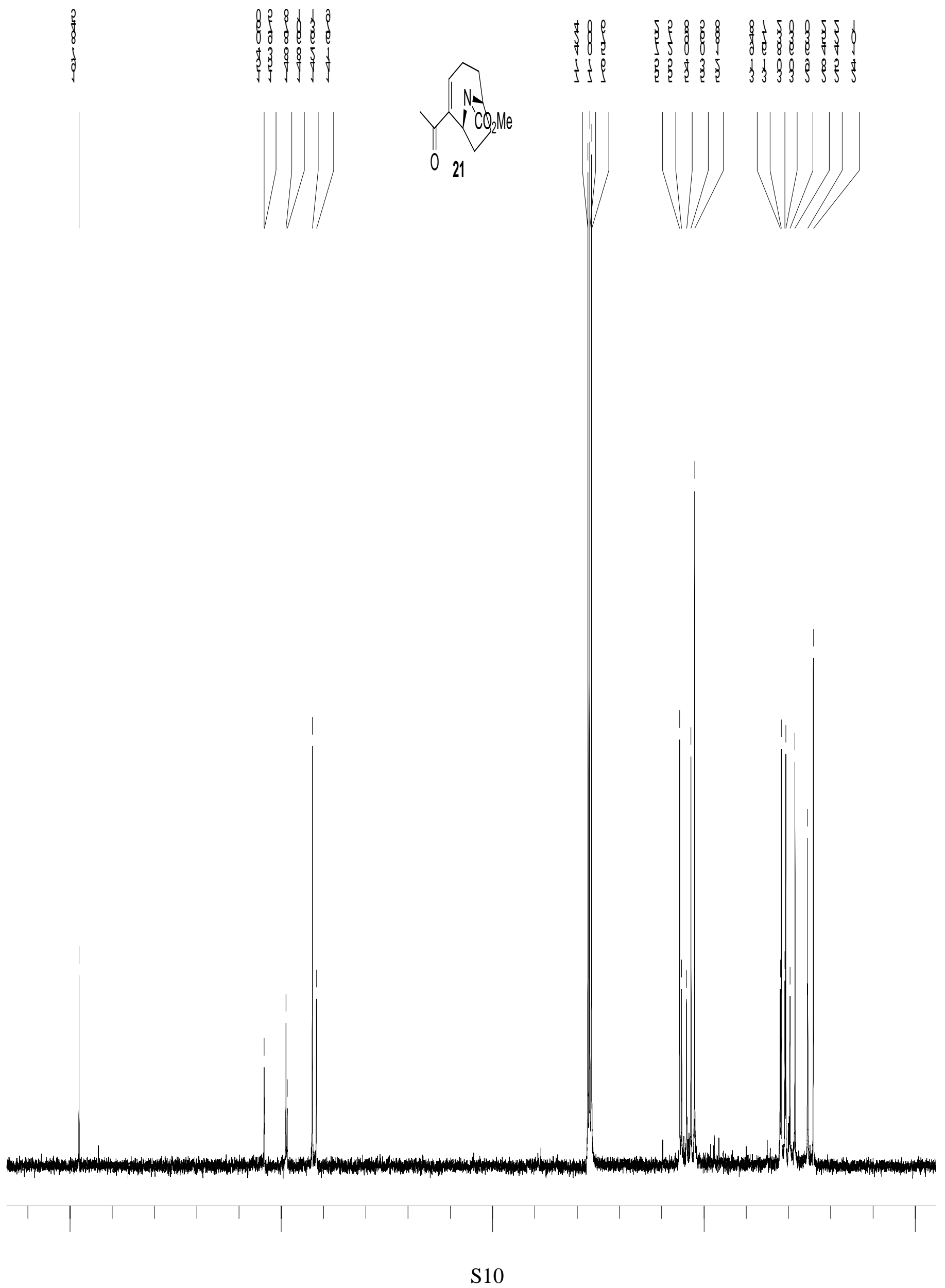


